\title{
Spaceborne potential for examining taiga-tundra ecotone form and vulnerability
}

\author{
Paul M. Montesano ${ }^{1,2}$, Guoqing Sun ${ }^{2,3}$, Ralph O. Dubayah ${ }^{3}$, and K. Jon Ranson ${ }^{2}$ \\ ${ }^{1}$ Science Systems and Applications, Inc., Lanham, MD 20706, USA \\ ${ }^{2}$ Biospheric Sciences Laboratory, NASA Goddard Space Flight Center, Greenbelt, MD 20771, USA \\ ${ }^{3}$ University of Maryland, Department of Geographical Sciences, College Park, MD 20742, USA \\ Correspondence to: Paul M. Montesano (paul.m.montesano@nasa.gov)
}

Received: 9 November 2015 - Published in Biogeosciences Discuss.: 15 January 2016

Revised: 31 May 2016 - Accepted: 9 June 2016 - Published: 6 July 2016

\begin{abstract}
In the taiga-tundra ecotone (TTE), site-dependent forest structure characteristics can influence the subtle and heterogeneous structural changes that occur across the broad circumpolar extent. Such changes may be related to ecotone form, described by the horizontal and vertical patterns of forest structure (e.g., tree cover, density, and height) within TTE forest patches, driven by local site conditions, and linked to ecotone dynamics. The unique circumstance of subtle, variable, and widespread vegetation change warrants the application of spaceborne data including high-resolution $(<5 \mathrm{~m})$ spaceborne imagery (HRSI) across broad scales for examining TTE form and predicting dynamics. This study analyzes forest structure at the patch scale in the TTE to provide a means to examine both vertical and horizontal components of ecotone form. We demonstrate the potential of spaceborne data for integrating forest height and density to assess TTE form at the scale of forest patches across the circumpolar biome by (1) mapping forest patches in study sites along the TTE in northern Siberia with a multi-resolution suite of spaceborne data and (2) examining the uncertainty of forest patch height from this suite of data across sites of primarily diffuse TTE forms. Results demonstrate the opportunities for improving patch-scale spaceborne estimates of forest height, the vertical component of TTE form, with HRSI. The distribution of relative maximum height uncertainty based on prediction intervals is centered at $\sim 40 \%$, constraining the use of height for discerning differences in forest patches. We discuss this uncertainty in light of a conceptual model of general ecotone forms and highlight how the uncertainty of spaceborne estimates of height can contribute to the uncertainty in identifying TTE forms. A focus on reducing the uncer-
\end{abstract}

tainty of height estimates in forest patches may improve depiction of TTE form, which may help explain variable forest responses in the TTE to climate change and the vulnerability of portions of the TTE to forest structure change.

\section{Introduction}

\subsection{TTE vegetation structure and processes}

The circumpolar biome boundary between the boreal forest and Arctic tundra - also known as the tree line, the foresttundra ecotone, or the taiga-tundra ecotone (TTE) - is an ecological transition zone covering $>1.9$ million $\mathrm{km}^{2}$ across North America and Eurasia (Payette et al., 2001; Ranson et al., 2011). This ecotone is among the fastest warming on the planet (Bader, 2014). The location, extent, structure, and pattern of vegetation in the TTE influences interactions between the biosphere and the atmosphere through changes to the surface energy balance and distribution of carbon (Bonan, 2008; Callaghan et al., 2002a). These TTE vegetation characteristics also affect local and regional Arctic and subarctic biodiversity (Hofgaard et al., 2012) and are controlled by a variety of factors that are scale-dependent (Holtmeier and Broll, 2005). At local scales the spatial configuration of trees is determined largely by site-level heterogeneity in hydrology, permafrost, disturbance, topography (aspect, slope, elevation), land use, and the geomorphologic conditions associated with each (Dalen and Hofgaard, 2005; Danby and Hik, 2007; Frost et al., 2014; Haugo et al., 2011; Holtmeier and Broll, 2010; Lloyd et al., 2003). 
North of the Kheta River in central Siberia (e.g., $71.9^{\circ} \mathrm{N}$, $\left.101.1^{\circ} \mathrm{E}\right)$, the TTE exhibits a change in forest structure across a gradient of open-canopy (discontinuous) forest from south to north. In this region, latitude coarsely controls TTE forest structure characteristics, which feature a general decrease in height and cover from south to north, as well as a variety of spatial patterns of trees (Holtmeier and Broll, 2010). These structural characteristics influence a range of TTE biogeophysical and biogeochemical processes in a number of ways. Forest structure provides clues as to the extent of sites with high organic matter accumulation and below-ground carbon pools (Thompson et al., 2016). Recent work notes that rapid growth changes individual tree forms, thus altering recruitment dynamics (Dufour-Tremblay et al., 2012). Height and canopy cover of trees and shrubs affect site-level radiative cooling, whereby larger canopies increase nocturnal warming and influence regeneration (D'Odorico et al., 2012). Such tree height and canopy controls over the transmission of solar energy have been well documented (Davis et al., 1997; Hardy et al., 1998; Ni et al., 1997; Zhang, 2004). The height and configuration of vegetation also partly influence permafrost by controlling snow supply, creating heterogenous ground and permafrost temperatures (Roy-Léveillée et al., 2014). Accounting for vegetation heterogeneity in schemes addressing surface radiation dynamics helps address the effects on rates of snowmelt in the boreal forest (Ni-Meister and Gao, 2011). Modeling results support the importance of tree heights on boreal forest albedo, which is a function of canopy structure, the snow regime, and the angular distribution of irradiance ( $\mathrm{Ni}$ and Woodcock, 2000). Better representation of vegetation height and cover is needed to improve climate prediction and understand vegetation controls on the snow-albedo feedback in the high northern latitudes (Bonfils et al., 2012; Loranty et al., 2013). Furthermore, the structure of vegetation in the TTE helps regulate biodiversity, where the arrangement of groups of trees provides critical habitat for Arctic flora and fauna (Harper et al., 2011; Hofgaard et al., 2012).

\subsection{A conceptual model of the TTE: forest patches, ecotone form, and the link to structural vulnerability}

The TTE, and other forest ecotones, can be conceptualized as self-organizing systems because of the feedbacks between the spatial patterns of groups of trees and associated ecological processes (Bekker, 2005; Malanson et al., 2006). In this conceptual model groups of trees with similar vertical and horizontal structural characteristics can be represented as forest patches. These patches have ecological meaning, because they reflect similar site history and environmental factors. At a coarser scale, these patterns and structural characteristics of TTE forest patches have been conceptualized with a few general and globally recognized ecotone forms (Harsch and Bader, 2011; Holtmeier and Broll, 2010). In the
TTE, these general ecotone forms (diffuse, abrupt, island, krummholz) reflect the spatial patterns of forest patches that are described by the horizontal and vertical structural characteristics of trees (e.g., canopy cover, height, and density) and have different primary mechanisms controlling tree growth.

The variation in ecotone form may help explain differing rates of TTE forest change across the circumpolar domain. These forms tend to vary with site factors, which may partly control the heterogeneity of change seen across the circumpolar TTE (Harsch and Bader, 2011; Lloyd et al., 2002). Further investigation is needed into the link between observed changes in vegetation, their pattern, and local factors that may control these changes (Virtanen et al., 2010). Epstein et al. (2004) provide a synthesis of how TTE patterns and dynamics are linked, and explain that a better understanding of vegetation transitions can improve predictions of vegetation sensitivity. Their observations provide a basis for the inference that TTE structure is most susceptible to temperature-induced changes in its structure where its structure is temperature-limited. Thus, the structural vulnerability of the TTE may be broadly defined as the susceptibility of its vegetation structure to changes that result in shifts in its geographic position and changes to its spatial pattern of trees. Vulnerable portions of the TTE are areas most likely to experience changes in forest structure that alter TTE structural patterns captured by forest patches and described by ecotone form.

\subsection{Towards identifying TTE form: spaceborne data integration, scaling, and the uncertainty of TTE structure}

Spaceborne remote-sensing data may facilitate identifying TTE form and linking it to local site factors and structural vulnerability (Callaghan et al., 2010, 2002b; Harsch and Bader, 2011; Kent et al., 1997). The way in which spaceborne data are integrated and scaled may be a key part of identifying structural patterns and TTE form. Fine-scale data can resolve individual trees that, when grouped to patches, may reveal ecotone forms (Danby and Hik, 2007; Hansen-Bristow and Ives, 1985; Hofgaard et al., 2009, 2012; Holtmeier and Broll, 2010; Mathisen et al., 2013). Without resolving groups of individual trees, coarse studies of the land surface may misrepresent ecotone form, be less frequently corroborated with ground data, and disguise the structural heterogeneity of discontinuous forests. In a TTE landscape this structural heterogeneity is critical for understanding biodiversity; biogeochemical and biophysical characteristics such as carbon sources, sinks, and fluxes; permafrost dynamics; surface roughness; albedo; and evapotranspiration (Bonan, 2008). Furthermore, understanding at a fine scale where the TTE is likely to change may improve understanding of the potential effects of changing TTE structure on these regional and global processes. 
A forest patch approach to the integration of multiresolution remote-sensing data may mitigate data scaling issues with regard to forest structure estimates. One example of mitigation is the misrepresentation of forest structure that arises with the sole use of coarse data. Medium-resolution sensors such as Landsat and Advanced Land Observation Satellite (ALOS) may not be suited for identifying the patch boundaries at the resolution required to study TTE structure. However, their spectral or backscatter information may still have value for predicting patch characteristics when combined with the spatial detail of high-resolution spaceborne imagery (HRSI) to define patch boundaries. Such an approach integrates coarser data into an analysis while maintaining the spatial fidelity of feature boundaries. Furthermore, a patch-level analysis helps attenuate high-frequency noise in image data. For example, ALOS Phased Array type L-band Synthetic Aperture Radar (PALSAR) backscatter has significant pixel-level speckle (Le Toan et al., 2011; Mette et al., 2004; Shamsoddini and Trinder, 2012) which, when grouped with coincident HRSI patch boundaries, can be averaged to reduce the noise and quantified further with a variance estimate.

In particular, data integration and scaling may also help mitigate the uncertainty of spaceborne estimates of vertical structure in discontinuous TTE forests. A spaceborne assessment of forest structure from individual active sensors across a gradient of boreal forest structure shows broad ranges of uncertainty at plot scales (Montesano et al., 2014a, 2015). These plot-scale studies provide an indication of the scale at which TTE structure changes. A spaceborne remote-sensing approach that identifies forest patch boundaries with HRSI may provide insight into TTE structural characteristics that are indicative of general ecotone forms at scales that are dictated by the variation of TTE forest structure itself. As such, a patch-based approach to capturing forest height and forest height uncertainty in the ecotone capitalizes on the added value that estimates of horizontal structure may provide for reducing uncertainties in estimates of vertical structure from remote sensing.

An evaluation of forest structure uncertainty serves the long-term goal of monitoring change over time and between sites, as well as distinguishing the portions of the TTE that are vulnerable to changes in forest height, cover, or density from those whose structure is more resilient and the rates associated with these changes (Epstein et al., 2004). The spatial patterns of this structural vulnerability will help models predict the consequences of TTE structural change on regional and global processes.

This work examines the uncertainty of mapped forest patch heights using a spaceborne remote-sensing data integration approach. We map forest patches with HRSI data $(<5 \mathrm{~m})$ to spatially assemble a medium-spatial-resolution (5$50 \mathrm{~m}$ ) suite of measurements from multispectral optical and synthetic aperture radar (SAR) with light detection and ranging (lidar) samples to estimate and model forest height and its uncertainty by forest patch. We discuss the implication of this uncertainty for both identifying TTE form and predicting dynamics, with regard to identifying portions of the TTE whose forest structure is vulnerable to temperature-induced changes.

\section{Methods}

\subsection{Study area and ground reference data}

Our study area encompasses a region of the TTE in northern Siberia in which we identified forest patch mapping sites and incorporated existing calibration and validation field plot and stand data. The region is subject to a severe continental climate, generally exhibits a gradient in tree cover from discontinuous to sparse; features elevations generally $<50 \mathrm{~m}$ a.s.l.; and is underlain with continuous permafrost (Bondarev, 1997; Naurzbaev et al., 2004). The forest cover - exclusively Larix gmelinii across all mapping, calibration and validation sites - exists at the climatic limit of forest vegetation, coinciding closely with the July $10^{\circ} \mathrm{C}$ isotherm (Osawa and Kajimoto, 2009). Tall shrubs - including Alnus sp., Betula sp., and Salix sp. - and dwarf shrubs (e.g., Vaccinium sp.) occur along with sedge-grass, moss, and lichen ground covers.

The mapping sites are primarily situated on the KhetaKhatanga Plain, north of the Kheta River, which is a tributary of the Khatanga River flowing north into the Laptev Sea. One site, which sits just south of the Novaya River on the Taymyr Peninsula, includes a portion of Ary-Mas, the world's northernmost forest (Bondarev, 1997; Kharuk et al., 2007; Naurzbaev and Vaganov, 2000). Mapping sites were chosen based on the presence of cloud-free multispectral and stereo pair data from HRSI available in the DigitalGlobe archive, and presence of patches of forest cover (Neigh et al., 2013). We visually interpreted HRSI to identify sites in this portion of the TTE where forest cover was discontinuous and where forest patches exhibited diffuse, abrupt, or island ecotone patch forms.

Ground reference sites were derived from two sources. The first consisted of individual tree measurements at circular plots ( $15 \mathrm{~m}$ radius) coincident with spaceborne lidar footprints, while the second comprised stand-level data specific to Larix gmelinii across a broader central Siberian region. The plot data, collected during an August 2008 expedition to the Kotuykan and Kotuy rivers, were used as either calibration or validation data in this study (Montesano et al., 2014b). Measurements were collected of tree diameters at breast height (DBH, $1.3 \mathrm{~m}$ ) and tree heights (clinometers for $97 \%$ of trees and tape measurement for $3 \%$ ) at plots coincident with spaceborne lidar footprints. The data used for this study included DBH for all tree stems with DBH $>3 \mathrm{~cm}$ $( \pm 0.1 \mathrm{~cm})$ and corresponding tree heights for each tree in each plot. These plot data, representing a range of discontin- 


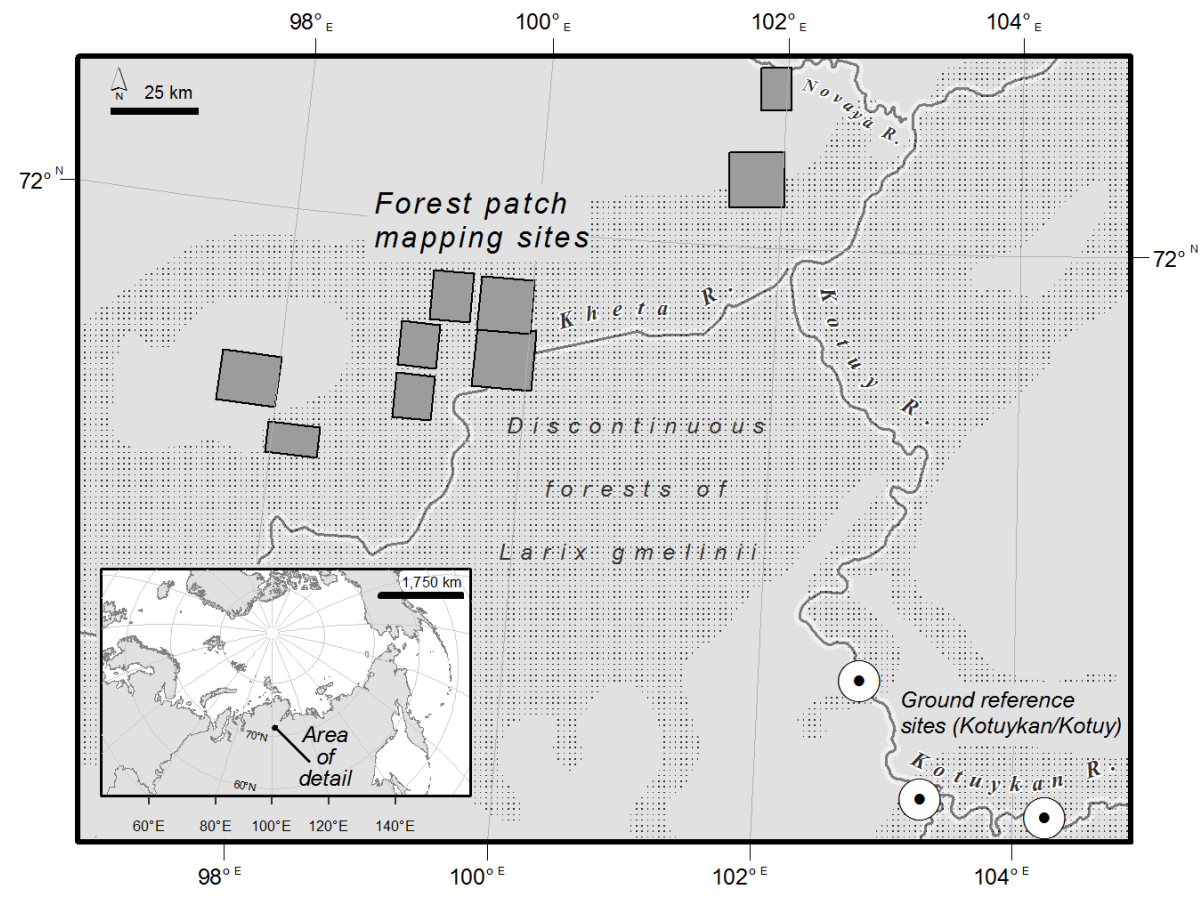

Figure 1. The study area in northern Siberia showing the nine forest patch mapping sites (boxes) and the ground reference sites along the Kotuykan River (circles) at which individual tree height measurements in circular plots coincident with spaceborne lidar footprints were collected.

uous Larix gmelinii forest conditions found across northern Siberia excluding prostrate tree forms, were supplemented with the stand data reported in Bondarev (1997). Shrub structure was not considered in this study.

The forest mapping and ground reference sites do not spatially coincide. This study examines the TTE on the KhetaKhatanga Plain, which exhibits a range of TTE forms, where the TTE covers a broader area, and where we had access to both stereo and multispectral HRSI data. While not spatially coincident, our ground reference sites characterize very similar forest conditions to those in the mapping sites. The main difference is that the ground reference sites feature an ecotone that is compressed, covering a smaller area due to topography, relative to the mapping sites. The type and structure of the Larix gmelinii forests are consistent across the broader region (Bondarev, 1997). The geographic footprints of all mapping sites for which forest patches were examined, as well as the general locations of Kotuykan/Kotuy ground reference sites, are shown in Fig. 1.

\subsection{Spaceborne data acquisition and processing}

A suite of spaceborne remote-sensing datasets were used in this study to delineate forest patch boundaries, assign forest patches with remote-sensing image pixel values, and predict forest patch height. Table 1 lists the individual datasets along with their period of acquisition. These data were collected within an $\sim 8$-year period (2004-2012) across sites during which, based on visual inspection of HRSI, there were no signs of disturbance from fires and for which the rate of tree growth is likely well below that which would be detectable from spaceborne data in that time interval. The data include spaceborne lidar data from the Ice, Cloud, and land Elevation Satellite's (ICESat) Geoscience Laser Altimeter System (GLAS) and image data from passive optical Landsat-7 Enhanced Thematic Mapper (ETM) and Worldview-1 \& -2, and SAR from ALOS PALSAR.

\subsubsection{Spaceborne lidar data}

The spaceborne lidar data from GLAS featured ground footprint samples $\sim 60 \mathrm{~m}$ in diameter (the actual footprint is an ellipse) of binned elevation returns of features within each footprint. These data provided ground surface elevation samples as described in a previous study (Montesano et al., 2014b). The set of GLAS data coincident with the digital surface model (DSM) of the study sites was filtered in an effort to remove lidar footprints for which within-footprint elevation changes precluded capturing heights of trees generally less than $12 \mathrm{~m}$ tall. The GLAS footprints used satisfied the following conditions; (1) the set of coincident DSM pixels had a standard deviation $\leq 5 \mathrm{~m}$, (2) the length of the lidar waveform was $\leq 20 \mathrm{~m}$, and (3) the difference between the maximum and minimum DSM values within a $10 \mathrm{~m}$ radius of the GLAS lidar centroid was $\leq 25 \mathrm{~m}$. This radius helped remove footprints for which there was a broad range of DSM 
Table 1. Summary of spaceborne datasets used to delineate or attribute forest patches.

\begin{tabular}{|c|c|c|c|}
\hline Dataset & Date & Attribute value & Spatial resolution \\
\hline $\begin{array}{l}\text { Landsat-7: } \\
\text { ETM cloud-free composite; } \\
\text { Vegetation continuous fields }\end{array}$ & ca. 2013 & $\begin{array}{l}\text { Top-of-atmosphere reflectance (mean): } \\
\text { SWIR, NIR, red, green; } \\
\text { Percent tree cover (mean) }\end{array}$ & $30 \mathrm{~m}$ pixel \\
\hline HRSI: Worldview-1 \& -2 & ca. 2012 & $\begin{array}{l}\text { DSM (mean, min, max, SD); } \\
\text { NDVI (mean), } \\
\text { Panchromatic roughness (mean); } \\
\text { CRM (mean, SD) }\end{array}$ & $\sim 0.5-2 \mathrm{~m}$ pixel \\
\hline ALOS PALSAR composite & $2007-2010$ & Backscatter power (HH, HV) & $25 \mathrm{~m}$ pixel \\
\hline ICESat-GLAS lidar & 2003-2006 & Ground surface elevation, waveform length & $\sim 60 \mathrm{~m}$ diameter footprint \\
\hline
\end{tabular}

values near the footprint centroid, indicative of terrain slope that would likely interfere with forest height estimation.

\subsubsection{Spaceborne image data}

Spaceborne image data covering the full extent of each study site were resampled from their original unprojected format during a reprojection into the Universal Transverse Mercator coordinate system (zone 48). The images were either medium ( $25-30 \mathrm{~m}$ pixels) or high $(<5 \mathrm{~m}$ pixels $)$ resolution. The medium-resolution spaceborne imagery included a Landsat-7 ETM multispectral cloud-free composite and vegetation continuous fields tree cover (VCF) products and ALOS PALSAR tiled yearly mosaics (2007-2010) (Hansen et al., 2013; Shimada et al., 2014). The four ALOS PALSAR yearly mosaics were processed into an average temporal mosaic of dual polarization (HH and HV) backscatter power. The high-resolution data consisted of HRSI multispectral (Worldview-2 satellite) and panchromatic (Worldview-1 satellite) data acquired from the National Geospatial Intelligence Agency via the NextView License agreement between Digital Globe and the US government (Neigh et al., 2013).

This HRSI was processed in accordance with Montesano et al. (2014b) to generate a DSM of elevations for each study site using the NASA Ames Stereo Pipeline software (Moratto et al., 2010; Montesano et al., 2014b). In addition to DSM generation, the HRSI data were processed to compute three additional image layers that were used to delineate and assign forest patches with the mean and variance of corresponding image pixel values. The steps below describe the processing of the three additional layers:

NDVI image: we computed a normalized difference vegetation index (NDVI) layer to create a mask separating areas of vegetation from non-vegetation within each mapping site. This widely used algorithm was based on the nearinfrared (NIR) and red channels of the multispectral HRSI $((\mathrm{NIR}-\mathrm{red}) /(\mathrm{NIR}+\mathrm{red}))$. This NDVI calculation, based on uncalibrated digital number values of image pixels, supported the objective of classifying forest structure patterns rather than maintaining the fidelity of reflectance characteristics.

Panchromatic image roughness: these roughness data were based on the textural characteristics of each site's panchromatic HRSI. Image roughness/texture information is useful for examining horizontal forest structure, a component of which is tree density (e.g., Wood et al., 2012, 2013). We computed image roughness using the output layers from the bright and dark edge detection (described in steps 10-12 of Table 2 in Johansen et al.) (Johansen et al., 2014). This image roughness derivation is resolution independent in that feature roughness can be captured as long as those features are resolved in the imagery. Here, we use $\sim 60 \mathrm{~cm}$ data to quantify a signal from groups of Larix gmelinii trees. The output from this roughness computation was a single image layer showing increased brightness values corresponding to increasingly textured surface features that is a result of the arrangement of trees across the landscape.

Canopy roughness model: the second of two image roughness layers, a canopy roughness model (CRM), was calculated from each DSM. A low-pass (averaging) filter (kernel size $=25 \times 25$ ) was applied to a version of the DSM that was resampled to decrease the spatial resolution by a factor of 8 . The filtering generated a smoothed terrain elevation (elev terrain) layer that removed the elevation spikes from the discontinuous tree cover that is evident in the DSM. This elev $_{\text {terrain }}$ layer was then resampled to the original spatial resolution. Surface feature roughness was computed as the difference between the DSM and elev $v_{\text {terrain }}$, and was represented as heights above elev terrain.

\subsection{Forest masking, patch delineation, and value assignment}

We analyzed forest structure at the study sites by masking forest area, delineating forest patch boundaries, and assigning these patches with remotely sensed data values in order to model forest patch height. This delineation and value assignment framework used the segmentation algorithms in 
Definiens Developer 8.7 (Benz et al., 2004). This framework modifies the multi-step, iterative segmentation and classification procedure discussed in previous work (Montesano et al., 2013). The central difference is that this approach uses exclusively data from HRSI to identify a vegetation mask and refine it to create a forest mask. We applied a segmentation to this forest mask to separate distinct forest patches and then assigned those patches the mean and standard deviation of pixel values from all coincident data.

Creating the forest mask was an iterative process that included segmentation and thresholding of the NDVI and two roughness layers. The thresholds used to classify forest were based on preliminary interpretation of the Larix gmelinii forest and non-forest areas in imagery across all forest patch mapping sites. The goal of this preliminary exploratory work was to understand the range of roughness and NDVI values associated with forest identified with visual interpretation of the particular set of imagery used. This exploratory work identified thresholds that were image independent and could be used in an automated patch classification protocol across all sites. However, these thresholds are sensitive to the seasonality of vegetation and, likely, the sun-sensor-target geometry at which the imagery was acquired. A detailed examination of the trade-offs associated with threshold choices and forest mask results was not part of this work.

The preliminary vegetation mask, generated from the initial separation of vegetation and non-vegetation within mapping sites, was based on an unsupervised contrast-based segmentation of the NDVI layer. This first masking step was further modified with NDVI and image roughness thresholding steps to compile a final forest mask. Next, we used both the panchromatic-derived roughness layer and the DSM-derived CRM to capture vegetation roughness and modify the preliminary vegetation mask. Thresholds were applied to these two roughness layers to create a forest mask sub-category. First, forest was separated from non-forest based on a panchromatic HRSI roughness threshold value $=5.5$, where higher values represented rougher vegetation and were classified as forest. Second, the forest mask was refined with information from the CRM. A CRM threshold value $=1$ was used to reclassify existing non-forest regions into the forest class. In the final step of this iterative forest-masking process, remaining non-forest areas with a mean roughness $>3$ and mean NDVI $<0.25$ were classified as forest. This helped classify remaining vegetation whose roughness value suggested forest vegetation but whose NDVI value had initially excluded them from this class.

The forest mask provided the extent for which a two-step procedure separated distinct forest patches before assigning patches with image values. First, this forest mask was divided to separate portions of forest whose roughness values were $>2$ standard deviations above the median roughness value. Next, patches were broken apart according to surface elevation values provided from each site's DSM. Patches were assigned with the mean and standard deviation of image pixel values within the boundary of each patch. Patch area was calculated to exclude patches below the minimum mapping unit of 0.5 ha. The remaining patches coincident with lidar footprint samples were assigned forest patch height values via the direct height estimation approach discussed below.

\subsection{Predicting forest patch height directly at lidar footprints}

GLAS lidar sampling of forest canopy height provided a means to estimate average patch canopy height through direct spaceborne height measurements. Where forest patches coincided with lidar footprints from GLAS, the canopy surface elevation from the DSMs and the ground elevation from either the DSMs or GLAS within a GLAS lidar footprint provided a sampling of forest height within the patch. First, we applied the methodology presented in Montesano et al. (2014b) to compile spaceborne-derived canopy height within GLAS lidar footprints and convert those heights to plot-scale maximum canopy height with a linear model (Montesano et al., 2014b). Finally, these plot-scale canopy height predictions from all GLAS lidar footprints within a given patch were used to directly determine the mean predicted forest patch height and the mean height error from the prediction interval of the canopy height linear model.

\subsection{Modeling forest patch height indirectly}

Canopy height predictions were made indirectly for forest patches without direct spaceborne sampling of forest canopy height. This indirect method, used for the vast majority ( $\sim 90 \%)$ of forest patches $>0.5$ ha across the study sites, involved (1) building a model from the set of forest patches with GLAS lidar samples relating the predicted forest patch canopy height (response variable) to patch values from the spaceborne image data summarized in Table 1 (predictor variables) and (2) applying that model to predict forest patch canopy height for those patches with no direct spaceborne height samples. These methods, described in Montesano et al. (2013) and Kellndorfer et al. (2010), use the random forest regression tree approach for prediction (Breiman, 2001; Kellndorfer et al., 2010; Montesano et al., 2013). This approach includes specifying both the number of decision trees that are averaged to produce the random forest prediction and the number of randomly selected predictor variables used to determine each split in each regression tree. The result is a prediction model that is valid for the range of predictions on which the model was built and reduces overfitting, or the degree to which the prediction model is applicable to only the specific set of input data. 


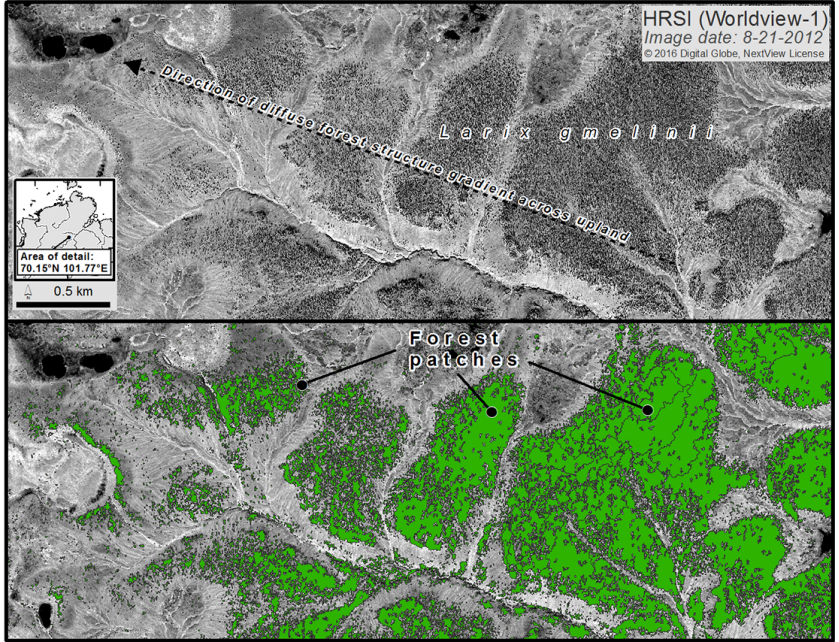

Figure 2. A representative example of forest patches showing a diffuse forest structure gradient of Larix gmelinii across an upland site delineated from HRSI. The top image shows a subset of a Worldview-1 panchromatic image from 21 August 2012 in one of the forest patch mapping sites. The bottom image shows the same subset with forest patches overlaid (green).

\section{Results}

\subsection{Forest patch delineation and direct sample density}

The forest patch was the fundamental unit of analysis in this study for which forest height was assigned either directly from spaceborne data at GLAS lidar footprints or indirectly from spaceborne data by means of empirical modeling with random forest. A representative example of a group of forest patches characteristic of a diffuse forest structure gradient delineated within the study area is shown in Fig. 2. Across the nine study sites, 3931 forest patches $>0.5$ ha were delineated based on NDVI, image roughness, and DSMs all from the HRSI data. Of this total, 364 patches $(9 \%)$ coincided with at least one GLAS lidar footprint at which a height sample was computed and used in the direct estimation of patch canopy height (Fig. 3a). The bimodal distribution that features a peak in the number of forest patches $\sim 1$ ha in size is evidence of the heterogeneous nature of forest cover in this region. The plots in Fig. 3b group forest patches, for which direct height estimates were made, into categories based on patch area. They show the general distribution of sampling density of direct height estimates within these patches. All patches with direct height samples featured a sampling density of $<3$ samples ha ${ }^{-1}$. The majority $(94 \%)$ of sampled patches had sampling densities $<0.5$ samples ha ${ }^{-1}$, of which most had patch areas $>10 \mathrm{ha}$. Larger patches have lower sampling densities in part because of the irregular arrangement of GLAS lidar tracks across the landscape.
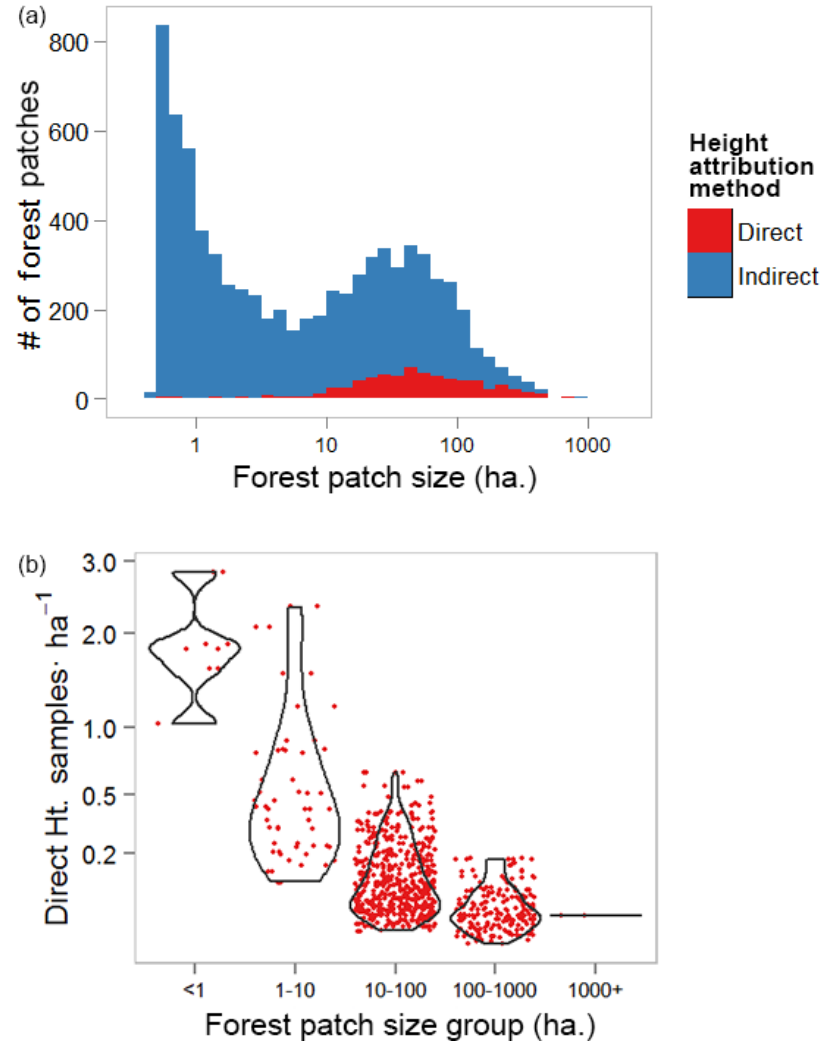

Figure 3. (a) The distributions of forest patch size in hectares according to height attribution method. (b) The distribution of direct height sample density (shown as violin plots) for each forest patch size group, overlain with dots representing individual patches (red).

\subsection{Forest height calibration and validation}

Forest height calibration and validation data were used to build and assess the empirical model for direct spaceborne estimates of height. Figure 4a shows sites for which ground reference calibration and validation data were collected. In Fig. $4 \mathrm{~b}$, the corresponding distributions of mean plot or stand height are shown for these sites. Measurements were collected in plots along the Kotuykan River for this study ( $n=$ $69)$ and those from regionally coincident stands $(n=40)$ at six sites across northern Siberia from Bondarev (1997).

A portion of the Kotuykan/Kotuy River plots were used to calibrate $(n=33)$ the model used to estimate spaceborne canopy height at plot scales after Montesano et al. (2014b), which was applied in the direct spaceborne estimation of forest patch height (Montesano et al., 2014b). The remaining portion of the Kotuykan/Kotuy River plots $(n=36)$ and stands from Bondarev (1997) $(n=40)$ served as independent validation of the distribution of forest patch heights derived from direct spaceborne height estimation (Bondarev, 1997). Mean heights of forest patches, plots, and stands were used to compare distributions of calibration and validation data because this was the height metric that was consistently avail- 

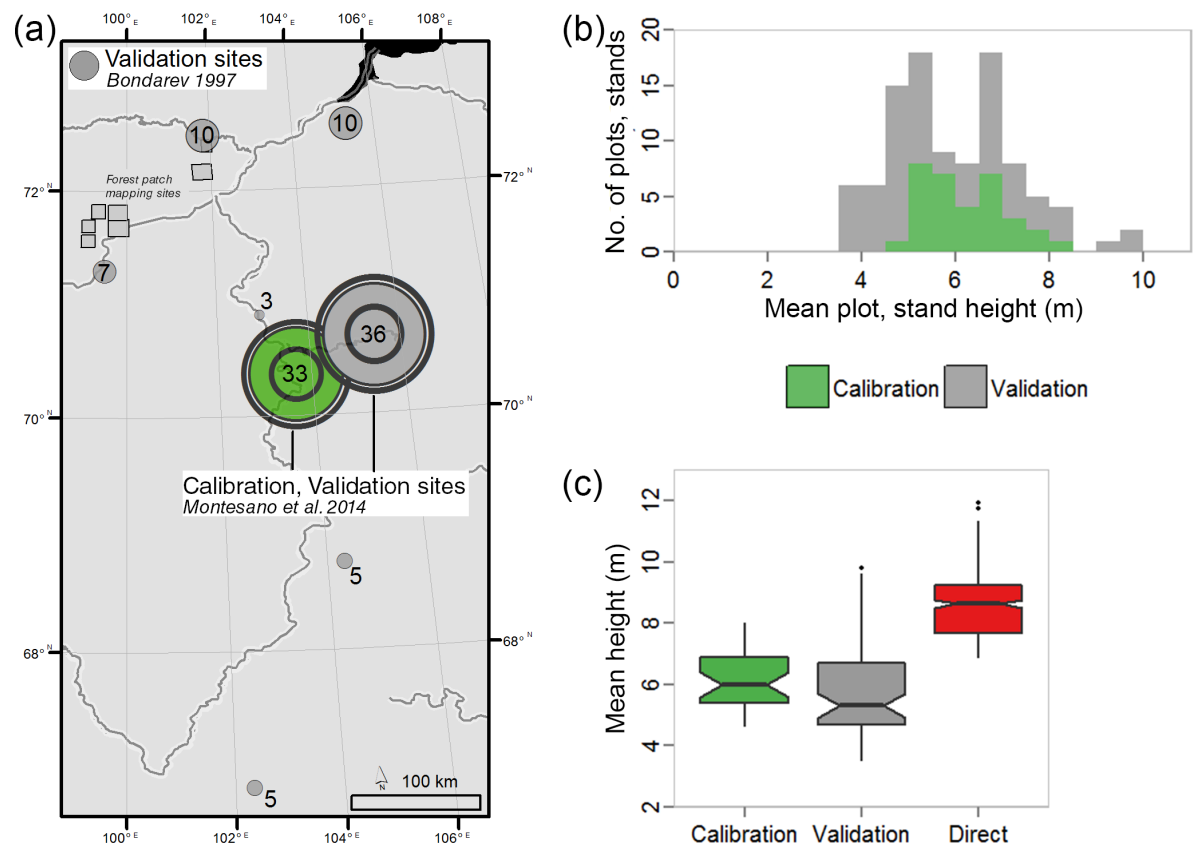

Figure 4. (a) Map of locations of calibration (green) and validation (grey) sites in northern Siberia with the number of stands or plots associated with each site. The circles representing general site locations are sized according to the number of stands. (b) Histogram of mean plot and stand heights from calibration and validation data. (c) Comparison of the distribution of mean height of calibration and validation plots and stands with that of forest patches heights from direct estimates. Notched boxplots showing the 25th, 50th, and 75th percentiles of mean height as horizontal lines and 1.5 times the interquartile range as vertical lines. Notches roughly indicate the $95 \%$ confidence interval for the median.

able across the set of forest patches, the calibration plots, and the validation plots and stands. The distributions in Fig. 4c show the proportion of forest patch heights for which direct spaceborne estimates of height were made. This distribution of direct spaceborne estimates of forest patch heights is shown alongside the distributions of individual tree measurements averaged across plots or stands from (1) the calibration plots in Montesano et al. (2014b), (2) the remaining Kotuykan/Kotuy River validation plots, and (3) the validation stands from Bondarev (1997).

\subsection{Indirect forest patch height estimates}

Indirect spaceborne estimates of forest patch heights were made for the majority of patches examined. Maximum and mean forest heights were predicted for $91 \%$ of forest patches across the study sites. Random forest regression tree models for five sets of spaceborne data predictor variables were used to estimate maximum and mean patch height indirectly for patches with no coincident direct spaceborne height estimates. Figure 5 shows the residual standard error (RSE) and $R^{2}$ of the best-performing model (based on $R^{2}$ ) for each spaceborne data predictor set (a particular combination of spaceborne data). The predictor set "all" that included all spaceborne image data layers identified in Table 1 explained $>60 \%$ of overall variation in modeled patch height. This "all-data" model shows only incremental improvement over the model using only HRSI-derived predictors. The Landsat and ALOS spaceborne variables explain $<40 \%$ of variation within the modeled relationship between spaceborne predictors and patch height.

\subsection{Uncertainty of forest patch height estimates}

We assessed the best-performing random forest model for indirectly estimating maximum and mean forest patch heights. The best-performing models were those from the all-data predictor sets, described above, where the number of predictor variables was 14 and 15, for maximum and mean forest patch height, respectively. Assessments were based on model $R^{2}$ and root mean square error (RMSE) for the maximum and mean patch height models, where $50 \%$ of patches with direct height estimates from which the indirect models were built were used for model training and $50 \%$ were used for model testing. The results of a bootstrapping procedure to examine the distribution of $R^{2}$ and RMSE from the random forest models applied to the set of testing data are shown in Fig. 6a and b. The plots show the bootstrapped distributions of best-performing model $R^{2}$ and RMSE, and are overlain with boxplots. The random forest models for maximum and mean patch height explain $61 \%( \pm 14 \%$ at $2 \sigma)$ and $59 \%$ $( \pm 14 \%$ at $2 \sigma)$ of the variation with errors of $1.6 \mathrm{~m}( \pm 0.2 \mathrm{~m}$ 

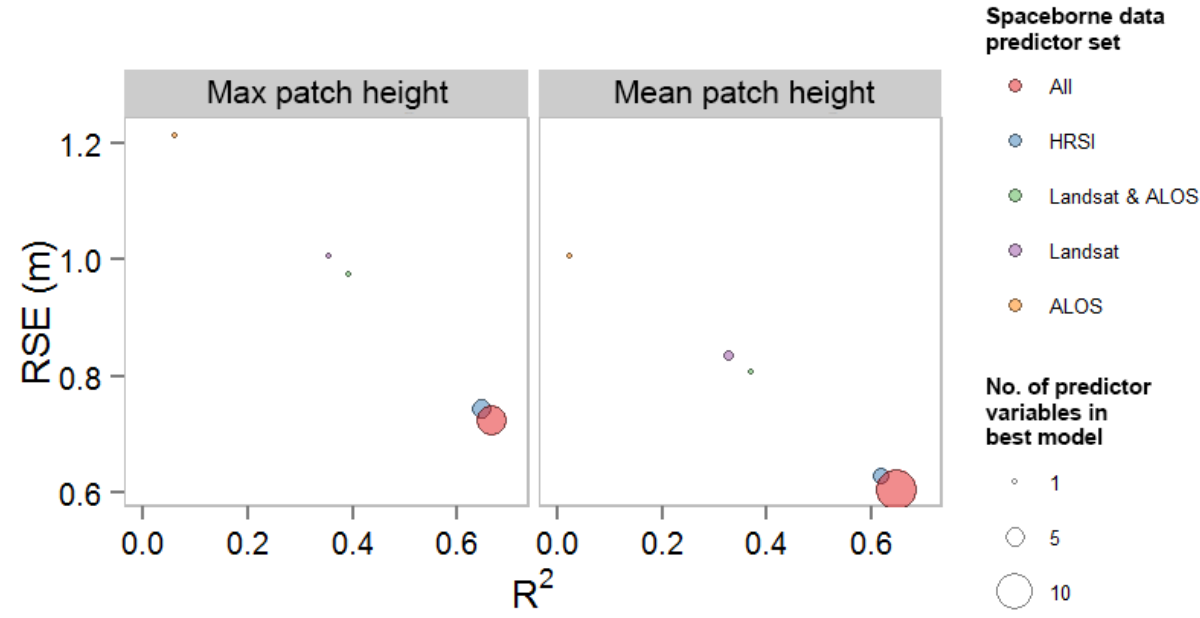

Figure 5. Results from random forest indirect forest patch height estimation for five spaceborne data predictor sets.

at $2 \sigma)$ and $1.3( \pm 0.2 \mathrm{~m}$ at $2 \sigma)$, respectively, where $2 \sigma$ represents the $95 \%$ confidence interval.

We computed $95 \%$ prediction intervals for patches receiving both direct and indirect height estimates. These prediction intervals show the uncertainty associated with patchlevel estimates of both maximum and mean patch heights. Figure $7 \mathrm{a}$ shows these height estimates and prediction intervals for all patches in this study across the continuum of patch sizes. Figure $7 \mathrm{~b}$ shows the relative prediction error, which was computed as the difference between the upper and lower prediction interval range divided by the predicted height value.

\section{Discussion}

Recent work suggests that TTE form may reflect which portions of the TTE have forest structure that is controlled primarily by temperature. With spaceborne remote sensing, various TTE forms across broad extents can be identified by characterizing the horizontal and vertical structure of trees. By identifying these forms, the controls of TTE forest structure may be inferred. The ability to characterize horizontal and vertical structure is a precursor both to (1) distinguishing one TTE form from another and (2) identifying areas where TTE form suggests tree growth is temperature limited. The intersection of such temperature-limited TTE forms with regional warming trends may point to areas where TTE forests are vulnerable to changes in its structure. Our work demonstrates the potential from spaceborne remote sensing for depicting a key structural characteristic of TTE form (height) and suggests where improvements are needed in order to identify portions of the TTE vulnerable to warming-induced structural changes.

This study's site-scale approach to examining forest structure is an example of a way to quantify the potential for change in forest structure and its effects on broader TTE dy- namics. Such detailed monitoring is needed to resolve both the variability in TTE forest structure at fine spatial scales and the variability in structural responses to changes in environmental drivers that are observed across the TTE. The high-resolution delineation of forest patches at our study sites in the TTE of northern Siberia demonstrates the detailed monitoring that is possible for examining spatial patterns of forest structure across the circumpolar domain, because of the use of spaceborne data. The forest patch height prediction intervals are estimates of the measurement error at the forest patch scale that explain existing constraints for discerning TTE form linked to changes in TTE forest structure.

We discuss the utility of the patch-based analysis, review the patch-level estimates of uncertainty, and then examine them in the context of a conceptual biogeographic model of TTE forest structure presented in the recent literature. Such a model helps clarify and focus spaceborne approaches to examining characteristics of TTE forest structure and its vulnerability to structural change.

\subsection{Patch-based TTE forest structure analysis}

The patch-based approach of remotely measuring TTE forest structure addresses the imperative for site-scale detail of TTE vegetation, whereby individual trees can be resolved, while acknowledging the influence of clusters of trees (patches) and their density on TTE attributes and dynamics. This approach coarsens the data, reducing spatial detail. However, from a biogeographic perspective, this reduction in detail is not arbitrary as are image pixel reductions when images are coarsened by means of down-sampling. Rather, image features and ancillary datasets inform the coarsening procedure, creating patch boundaries that are based on spectral and textural characteristics of images as well as other landscape information. Polygonal patches, particularly when vegetation patterns and heterogeneity are key landscape features, may 

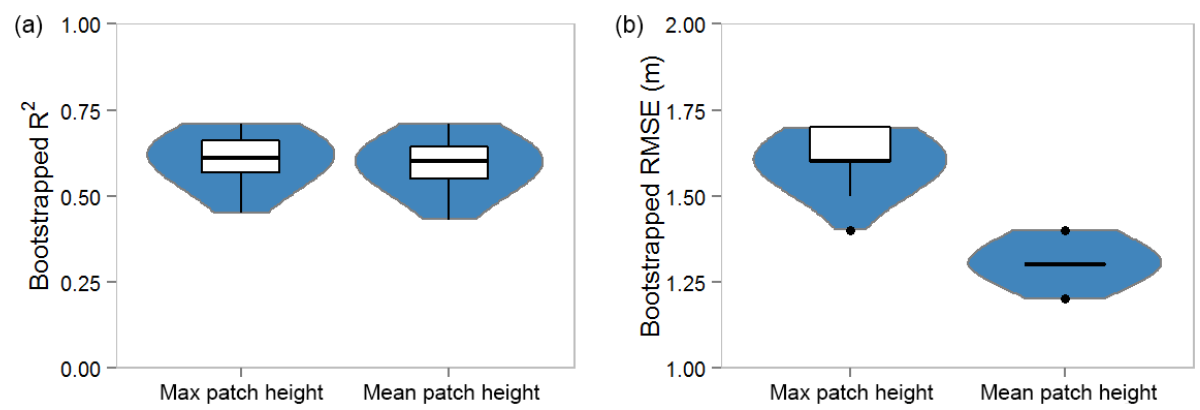

Figure 6. The bootstrap-derived distributions (shown as violin plots, blue) of the random forest model's (a) $R^{2}$ and (b) RMSE for the indirect forest patch height prediction method whereby all spaceborne variables were used to predict maximum and mean forest patch height. Box plots (white) show the 25th and 75th percentiles (lower and upper lines), median (dark line), and $1.5 \times$ the interquartile range (whiskers). Data beyond the whiskers are shown as points.

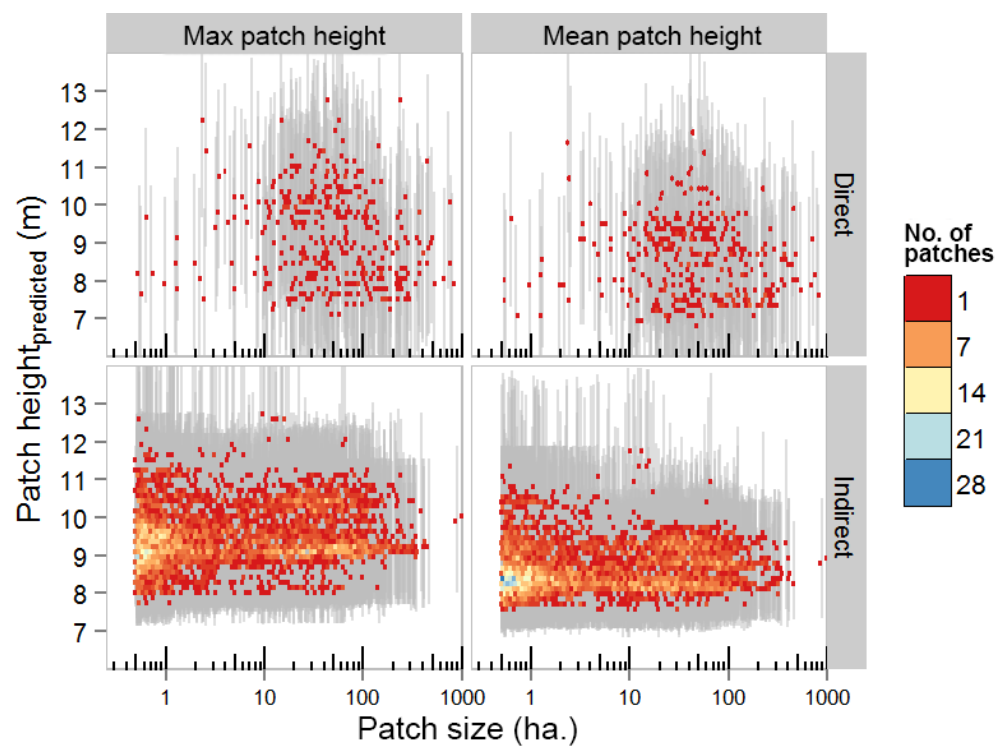

Figure 7. (a) Patch height and $95 \%$ prediction intervals (grey lines) for patches from direct prediction and indirect prediction shown across the continuum of patch sizes. (b) Distributions of relative prediction error (95\% prediction interval) for patch height predictions.

be more informative than pixels, particularly for studies at fine scales. Furthermore, patches provide a means to integrate remote-sensing data across an area and extend sample measurements (Kellndorfer et al., 2010; Lefsky, 2010; Montesano et al., 2013; van Aardt et al., 2006; Wulder and Seemann, 2003; Wulder et al., 2007). We note that shrub structure was not accounted for in our field data and not directly addressed with our patch height analysis. However, it is likely that signals from shrubs persisted in the forest mask used to estimate patch structure and, thus, may be incorporated into estimates of patch height and uncertainty.

\subsection{Forest patch height uncertainty}

There are four central results regarding the uncertainty of forest patch height across the study area. The first two involve the sampling of canopy height within forest patches, while the last two focus on its modeling. These local-scale results for the TTE are then contrasted with existing global-scale estimates of forest height.

The way in which forest patch heights are sampled affects estimates. First, direct forest patch height estimates from a combination of coincident GLAS lidar ground surface and HRSI DSM-derived canopy elevations were made for $\sim 9 \%$ of forest patches in the study area. Second, the sampling density of these direct height estimates, driven by the sampling scheme of the spaceborne lidar, is $<0.5$ samples ha ${ }^{-1}$ for $94 \%$ of sampled patches. This sampling density is well below the critical density of 16 sample ha $^{-1}$ recommended for sampling forest biomass at the 1 ha plot scale (Huang et al., 2013). These results suggest that the cost of increasing forest patch sizes is a decrease in the density of direct height measurements. This is likely an artifact of the GLAS sampling scheme, whose sampling is regular in the along- 
track direction ( 1 sample every $\sim 170 \mathrm{~m}$ ), but whose coverage of ground tracks was highly irregular across forested areas. Such a sampling scheme likely increases patch height uncertainty, thus limiting the ability to discern ecotone form.

The modeling of forest patch height provided some insight into what drives the prediction of height and the associated uncertainty of predictions. First, the model that explained the most variation included all remote-sensing image data layers. However, this all-data model showed little improvement on that built from HRSI predictors. Furthermore, in the former, the most important variables were from HRSI. These variables, NDVI and the standard deviation of the canopy surface roughness, are indications of vegetation and its density within forest patches. This suggests that the mediumresolution data from ALOS and Landsat products are not strong predictors of vertical structure characteristics across the range of forest patch sizes identified in the study area, and that without HRSI inputs the heterogeneity of TTE forest structure at the scale of its change across the ecological transition zone from forest to tundra is lost.

Second, the errors reported for the "all-inputs" models predicting maximum and mean forest patch height show forest patch height errors, including error uncertainty at $<2 \mathrm{~m} \sigma$ (95\% confidence interval). However, the prediction intervals for these vertical structure metrics show the uncertainty in the predictions at the patch level of $\sim 40 \%$. These patch-level prediction intervals translate to a maximum patch height error of $\pm 4 \mathrm{~m}$ for patches with maximum heights of $10 \mathrm{~m}$. These errors indicate that patches with maximum heights of 5 and $10 \mathrm{~m}$ would be statistically indistinguishable on the basis of height. This is a problem for identifying diffuse TTE forms, for which forest patch and tree height is a key attribute, because these forms generally features a gradual decrease in tree height and cover across portions of the ecotone where present. Diffuse forms are the most likely type of general form to demonstrate tree line advance, where $80 \%$ of diffuse ecotone sites examined in a meta-analysis show such tree line advance (Harsch et al., 2009).

These local-scale uncertainties improve upon recent global-scale spaceborne maps of vegetation height. These maps feature height uncertainties (RMSE) of $\sim 6 \mathrm{~m}$, which are expected given that coarse-scale $(>500 \mathrm{~m})$ global maps of forest height aggregate many of these height measurement samples across broad spatial extents (Lefsky, 2010; Simard et al., 2011). This uncertainty can be the difference between the presence or absence of a forest patch in the TTE and is therefore not suited for evaluating the link between TTE forest structure and heterogeneous local-scale site factors. The height uncertainty of forest patches, $\sim 90 \%$ of which have prediction intervals less than $<50 \%$ of the predicted heights, improves the uncertainty and spatial resolution of TTE forest height measurements. However, this study's primary benefit is in the fidelity of the spatial extent of TTE forest patches. The scale of these patches are more appropriate than coarse-, global-scale estimates of forest structure for reporting site- specific forest structure estimates that are critical for understanding forest characteristics at this biome boundary in flux.

\subsection{Improving the estimates of forest patch height}

Estimates of forest patch height need to be improved to distinguish important patch characteristics. A potentially large source of uncertainty of patch height estimates may be attributed to the limitation of the approach of using direct height estimates for calibration of the indirect patch height prediction method. This approach for direct sampling of patch height, from differencing canopy and ground surface elevations within lidar footprints, involves sampling a very small portion of the overall patch. The assumption associated with delineating forest patches is that each patch itself is a homogenous unit with similar tree structure characteristics throughout. However, the extent to which this assumption holds was not examined. For patches with a high degree of tree structure heterogeneity, a single direct sample of height may not be sufficient to represent either maximum or mean patch heights. These data, when used to train a random forest model, will degrade the modeled relationship of mean patch-level image characteristics to patch height, because the sample used to determine patch height might not be representative of actual patch height.

There are two ways to address this source of uncertainty. The first is to accumulate more direct samples of forest heights within a patch. This can be accomplished by collecting more ground surface elevation estimates within forest patches. One way of doing this is with more lidar samples. The lidar data collected after the launch of ICESat-2 should add to the existing set of GLAS samples, contributing significantly to increasing ground surface elevation estimates in forested areas and adding enormous value to approaches that involve data integration from a variety of sensors. More ground surface elevation estimates can also be made by improving the way in which they are derived from HRSI DSMs. These improvements are needed because of higher errors associated with HRSI DSM ground surface elevation estimates within forested areas (Montesano et al., 2014b). Second, the homogeneity of forest patches can be improved by refining algorithms associated with delineating forest patches. This could include decreasing patch size, improving the canopy surface roughness algorithm (e.g., with tree-shadow fraction estimates), and including multi-temporal HRSI to help separate surface features whose reflectance characteristics differ throughout the growing season. These refinements may improve the modeling of forest patch height and ultimately the ability to discern diffuse TTE forms.

\subsection{Spaceborne depiction of TTE form}

The conceptual model of ecotone forms presented by Harsch and Bader (2011) describes form as a result of the relative dominance of different controlling mechanisms (Harsch and 
Bader, 2011). Only some of these mechanisms are primarily driven by climate. For the diffuse TTE form, the primary controlling mechanism of this conceptual pattern is the growth limitation of trees, whereby tree growth is driven by warming of summer or winter temperatures. This study featured two key approaches for depicting diffuse TTE forms that may improve insight into the vulnerability to climate warming of current TTE structure.

One key approach of this study involved integrating spatially detailed spaceborne observations. This integration provided a means to simultaneously account for the horizontal and vertical components of the spatial patterns of forest structure in the TTE that may help improve depictions of the diffuse TTE form. The recent literature on the patterns of trees in the TTE explains how tree density and height create varying forest patterns across the ecotone, that these patterns are important because they may provide clues as to the dynamics of TTE forest structure, and that they should be explored with detailed remote sensing (Bader et al., 2007; Harsch and Bader, 2011; Holtmeier and Broll, 2007).

A second key approach aggregates the spaceborne estimates of horizontal and vertical structure at the scale of forest patches. These patches provide a means to analyze the spatial pattern of forest structure. This scaling is critical, because it facilitates a standardized approach to TTE structure mapping that is appropriate for the broad spatial domain of the TTE while adhering to requirements of site-specific forest structure detail. This helps to explore the biogeography of TTE forest structure in the context of a conceptual model that highlights the importance of both TTE tree density and height.

In this study, tree density is accounted for in an indirect manner with the delineation of forest patches that use the horizontal structure captured with HRSI. This horizontal structure manifests itself as image texture or the frequency of vegetation across a spatial extent; it may also be related to surface roughness, canopy cover, or stem density, but a close examination of this relationship was not part of this study. The patch-based approach for aggregating height information was a means to break apart the forested portions of each site by reducing the heterogeneity in horizontal structure. Essentially, the use of the roughness information derived from HRSI helped establish a basis for the analysis of height by using it as a proxy for vegetation density and by expressing it as a contiguous patch that served as the fundamental unit by which height was aggregated. This data integration should provide more information for discerning diffuse TTE forms than individual assessments of either tree height or tree density.

The site-scale, patch-based treatment of the landscape is driven by two central needs. The first is the need for sitelevel understanding of TTE vegetation structure characteristics. The second is the need to understand the spatial patterns of trees across the landscape, because of the link between vegetation patterns and ecological processes. This analytical approach should be developed to more deeply explore the TTE vegetation patterns that variations in height and density reveal, such as patch size, shape, landscape position, connectivity, and spatial autocorrelation of varying types of forest patches across the TTE as well as the association of such patterns with permafrost and carbon flux dynamics.

\subsection{Implications for understanding TTE structure vulnerability}

Understanding the vulnerability of TTE structure is a key objective of research into expected changes in the high northern latitudes (Callaghan et al., 2002a). Multiple lines of evidence indicate that vegetation changes are occurring in the TTE and that these changes are heterogeneous across the circumpolar domain. The most rapid TTE vegetation responses to climate change will occur where climate is the main factor controlling TTE vegetation (Epstein et al., 2004). This suggests that TTE structure is most vulnerable at sites both controlled by and undergoing changes in climate. Currently, the reported patch-level forest height uncertainty constrains the identification of the portions of the TTE that are most vulnerable to forest structure change. However, this spaceborne approach framed by the conceptual model of TTE form provides a clear directive for near-term work of examining the biogeography of forest structure in the TTE, and understanding and forecasting vegetation responses in the TTE based on the susceptibility to structural changes (i.e., vulnerability) that these general patterns of forest structure suggest.

It is unlikely to derive the dominant mechanisms controlling TTE forest structure directly from remote sensing. However, these mechanisms may be inferred from remotely sensed TTE form. Depictions of diffuse TTE forms, resolved with improved maps of TTE patterns that incorporate forest patch height estimates, may provide evidence as to the general mechanisms that give rise to these diffuse forms (e.g., temperature-limited growth). Mapped TTE patterns, i.e., TTE form, would be useful for examining ecosystem dynamics in the high northern latitudes. These maps could be integrated with topographic, hydrologic, permafrost, and other climate data to suggest a gradient of TTE structure vulnerability. They would (1) provide information on the patterns of environmental variables that are the dominant drivers of tree growth; (2) provide insight into the influence of TTE structural changes on biodiversity (Hofgaard et al., 2012); and (3) inform plant community and forest gap models that combine temperature, soil, and disturbance data to examine the drivers of vegetation structure and forecast its potential for change in the TTE (Epstein et al., 2000; Xiaodong and Shugart, 2005). For example, understanding TTE form in areas where vegetation structural changes have been noted may help explain the variability of structure change. Furthermore, these depictions could also contribute to spatially explicit site index information in ecosystem process models to help account for the variability in predictions of TTE forest struc- 
ture dynamics across the circumpolar domain. This will aid long-term forecasting by suggesting the most likely sites, at fine scales, for changes to vegetation-disturbance feedbacks and the extent to which biogeophysical interactions may shift (e.g., vegetation effects on surface albedo). The vulnerability of TTE structure to temperature-induced change is one of many factors that may alter ecological processes in the high northern latitudes.

\section{Conclusions}

The vertical component of TTE form, maximum and mean forest patch height, as derived from a specific suite of spaceborne sensors at sites in northern Siberia, has an uncertainty of $\sim 40 \%$. With this uncertainty, forest patches with maximum heights of 5 and $10 \mathrm{~m}$ are statistically indistinguishable on the basis of height. Height is a key attribute of the diffuse TTE forms, which generally feature a gradual decrease of height and tree density across the ecotone and are the most likely form to demonstrate tree line advance. Differences in the heights of forest patches are a central feature of the diffuse TTE form where significant structural changes have been observed. These differences suggests that improving the remote sensing of patch height will provide a key variable needed for examining TTE forest structure. The conceptual model of TTE form should continue to guide the application of a patch-based, multi-sensor spaceborne data approach because of its potential for aggregating and scaling information provided by the structural patterns of groups of forest patches across the full TTE domain. Such patterns may help infer which portions of the TTE are most vulnerable to temperature-induced structural changes.

\section{Data availability}

Research data included a number of satellite data products, some of which are available to the public. The Landsat products are available through a partnership between the University of Maryland, College Park's Department of Geographical Sciences and Google Earth Engine at https://earthenginepartners.appspot.com/ science-2013-global-forest; ALOS PALSAR data are accessible through the University of Alaska Fairbanks' Alaska Satellite Facility at https://www.asf.alaska.edu/ sar-data/palsar; and ICESat-GLAS data are available through the National Snow and Ice Data Center at https://nsidc.org/ data/GLA14/versions/34. Worldview-1 \& -2 data are available to the US federal government from the US National Geospatial-Intelligence Agency pursuant to NextView license agreement with DigitalGlobe.
Acknowledgements. Funding for this work was provided by the NASA Terrestrial Ecology Program.

Disclaimer. The use of trade names is intended for clarity only and does not constitute an endorsement of any product or company by the federal government.

Edited by: T. Laurila

Reviewed by: four anonymous referees

\section{References}

Bader, J.: Climate science: The origin of regional Arctic warming, Nature, 509, 167-167, 2014.

Bader, M. Y., Rietkerk, M. and Bregt, A. K.: Vegetation Structure and Temperature Regimes of Tropical Alpine Treelines, Arct. Antarct. Alp. Res., 39, 353-364, 2007.

Bekker, M. F.: Positive feedback between tree establishment and patterns of subalpine forest advancement, Glacier National Park, Montana, USA, Arct. Antarct. Alp. Res., 37, 97-107, 2005.

Benz, U. C., Hofmann, P., Willhauck, G., Lingenfelder, I. and Heynen, M.: Multi-resolution, object-oriented fuzzy analysis of remote sensing data for GIS-ready information, ISPRS J. Photogramm., 58, 239-258, doi:10.1016/j.isprsjprs.2003.10.002, 2004.

Bonan, G. B.: Forests and Climate Change: Forcings, Feedbacks, and the Climate Benefits of Forests, Science, 320, 1444-1449, doi:10.1126/science.1155121, 2008.

Bondarev, A.: Age distribution patterns in open boreal Dahurican larch forests of Central Siberia, Forest Ecol. Manag., 93, 205214, 1997.

Bonfils, C. J. W., Phillips, T. J., Lawrence, D. M., Cameron-Smith, P., Riley, W. J., and Subin, Z. M.: On the influence of shrub height and expansion on northern high latitude climate, Environ. Res. Lett., 7, 015503, doi:10.1088/1748-9326/7/1/015503, 2012.

Breiman, L.: Random forests, Mach. Learn., 45, 5-32, 2001.

Callaghan, T. V., Bergholm, F., Christensen, T. R., Jonasson, C., Kokfelt, U., and Johansson, M.: A new climate era in the subArctic: Accelerating climate changes and multiple impacts, Geophys. Res. Lett., 37, L14705, doi:10.1029/2009GL042064, 2010.

Callaghan, T. V., Crawford, R. M., Eronen, M., Hofgaard, A., Payette, S., Rees, W. G., Skre, O., Sveinbjörnsson, B., Vlassova, T. K., and Werkman, B. R.: The dynamics of the tundra-taiga boundary: an overview and suggested coordinated and integrated approach to research, Ambio, Special Report 12, 3-5, 2002a.

Callaghan, T. V., Werkman, B. R., and Crawford, R. M.: The tundrataiga interface and its dynamics: Concepts and applications, Ambio, 1, 6-14, 2002b.

Dalen, L. and Hofgaard, A.: Differential regional treeline dynamics in the Scandes Mountains, Arct. Antarct. Alpine Res., 37, 284 296, 2005.

Danby, R. K. and Hik, D. S.: Variability, contingency and rapid change in recent subarctic alpine tree line dynamics, J. Ecol., 95, 352-363, doi:10.1111/j.1365-2745.2006.01200.x, 2007.

Davis, R. E., Hardy, J. P., Ni, W., Woodcock, C., McKenzie, J. C., Jordan, R., and Li, X.: Variation of snow cover ablation in the boreal forest: A sensitivity study on the effects of conifer canopy, J. Geophys. Res.-Atmos., 102, 29389-29395, 1997. 
D’Odorico, P., He, Y., Collins, S., De Wekker, S. F. J., Engel, V., and Fuentes, J. D.: Vegetation-microclimate feedbacks in woodland-grassland ecotones, Global Ecol. Biogeogr., 22, 364379, doi:10.1111/geb.12000, 2012.

Dufour-Tremblay, G., Lévesque, E., and Boudreau, S.: Dynamics at the treeline: differential responses of Picea mariana and Larix laricinato climate change in eastern subarctic Québec, Environ. Res. Lett., 7, 044038, doi:10.1088/1748-9326/7/4/044038, 2012.

Epstein, H. E., Beringer, J., Gould, W. A., Lloyd, A. H., Thompson, C. D., Chapin, F. S., Michaelson, G. J., Ping, C. L., Rupp, T. S., and Walker, D. A.: The nature of spatial transitions in the Arctic, J. Biogeogr., 31, 1917-1933, 2004.

Epstein, H. E., Walker, M. D., Chapin III, F. S., and Starfield, A. M.: A transient, nutrient-based model of arctic plant community response to climatic warming, Ecol. Appl., 10, 824-841, 2000.

Frost, G. V., Epstein, H. E., and Walker, D. A.: Regional and landscape-scale variability of Landsat-observed vegetation dynamics in northwest Siberian tundra, Environ. Res. Lett., 9, 025004, doi:10.1088/1748-9326/9/2/025004, 2014.

Hansen, M. C., Potapov, P. V., Moore, R., Hancher, M., Turubanova, S. A., Tyukavina, A., Thau, D., Stehman, S. V., Goetz, S. J., Loveland, T. R., Kommareddy, A., Egorov, A., Chini, L., Justice, C. O., and Townshend, J. R. G.: High-Resolution Global Maps of 21st-Century Forest Cover Change, Science, 342, 850-853, doi:10.1126/science.1244693, 2013.

Hansen-Bristow, K. J. and Ives, J. D.: Composition, Form, and Distribution of the Forest-Alpine Tundra Ecotone, Indian Peaks, Colorado, USA (Zusammensetzung, Form und Verbreitung des Übergangssaumes zwischen der Waldstufe und der alpinen Tundrastufe im Indian Peaks Gebiet, Front Range, Colorado, USA), Erdkunde, 286-295, 1985.

Hardy, J. P., Davis, R. E., Jordan, R., Ni, W., and Woodcock, C. E.: Snow ablation modelling in a mature aspen stand of the boreal forest, Hydrol. Process., 12, 1763-1778, 1998.

Harper, K. A., Danby, R. K., De Fields, D. L., Lewis, K. P., Trant, A. J., Starzomski, B. M., Savidge, R., and Hermanutz, L.: Tree spatial pattern within the forest-tundra ecotone: a comparison of sites across Canada, Can. J. Forest Res., 41, 479-489, doi:10.1139/X10-221, 2011.

Harsch, M. A. and Bader, M. Y.: Treeline form - a potential key to understanding treeline dynamics, Global Ecol. Biogeogr., 20, 582-596, doi:10.1111/j.1466-8238.2010.00622.x, 2011.

Harsch, M., Hulme, P., McGlone, M., and Duncan, R.: Are treelines advancing? A global meta-analysis of treeline response to climate warming, Ecol. Lett., 12, 1040-1049, 2009.

Haugo, R. D., Halpern, C. B., and Bakker, J. D.: Landscape context and long-term tree influences shape the dynamics of forestmeadow ecotones in mountain ecosystems, Ecosphere, 2, 91, doi:10.1890/ES11-00110.1, 2011.

Hofgaard, A., Dalen, L., and Hytteborn, H.: Tree recruitment above the treeline and potential for climate-driven treeline change, J. Veg. Sci., 20, 1133-1144, 2009.

Hofgaard, A., Harper, K. A., and Golubeva, E.: The role of the circumarctic forest-tundra ecotone for Arctic biodiversity, Biodiversity, 13, 174-181, doi:10.1080/14888386.2012.700560, 2012.

Holtmeier, F.-K. and Broll, G.: Sensitivity and response of northern hemisphere altitudinal and polar treelines to environmental change at landscape and local scales, Global Ecol. Biogeogr., 14, 395-410, 2005.
Holtmeier, F.-K. and Broll, G.: Treeline advance - driving processes and adverse factors, Landscape Online, 1, 1-32, doi:10.3097/LO.200701, 2007.

Holtmeier, K.-F. and Broll, G.: Altitudinal and polar treelines in the northern hemisphere Causes and response to climate change (Obere und polare Baumgrenze auf der nördlichen Hemisphäre Ursachen und Antwort auf den Klimawandel), Polarforschung, 79, 139-153, 2010.

Huang, W., Sun, G., Dubayah, R., Cook, B., Montesano, P., $\mathrm{Ni}$, W., and Zhang, Z.: Mapping biomass change after forest disturbance: Applying LiDAR footprint-derived models at key map scales, Remote Sens. Environ., 134, 319-332, doi:10.1016/j.rse.2013.03.017, 2013.

Johansen, K., Sohlbach, M., Sullivan, B., Stringer, S., Peasley, D., and Phinn, S.: Mapping Banana Plants from High Spatial Resolution Orthophotos to Facilitate Plant Health Assessment, Remote Sensing, 6, 8261-8286, doi:10.3390/rs6098261, 2014.

Kellndorfer, J. M., Walker, W. S., LaPoint, E., Kirsch, K., Bishop, J., and Fiske, G.: Statistical fusion of lidar, InSAR, and optical remote sensing data for forest stand height characterization: A regional-scale method based on LVIS, SRTM, Landsat ETM plus, and ancillary data sets, J. Geophys. Res.-Biogeo., 115, G00E08, doi:10.1029/2009JG000997, 2010.

Kent, M., Gill, W. J., Weaver, R. E., and Armitage, R. P.: Landscape and plant community boundaries in biogeography, Prog. Phys. Geogr., 21, 315-353, 1997.

Kharuk, V., Ranson, K., and Dvinskaya, M. L.: Evidence of Evergreen Conifer Invasion into Larch Dominated Forests During Recent Decades in Central Siberia, Eurasian Journal of Forest Research, 10, 163-171, 2007.

Le Toan, T., Quegan, S., Davidson, M. W. J., Balzter, H., Paillou, P., Papathanassiou, K., Plummer, S., Rocca, F., Saatchi, S., Shugart, H., and Ulander, L.: The BIOMASS mission: Mapping global forest biomass to better understand the terrestrial carbon cycle, Remote Sens. Environ., 115, 2850-2860, doi:10.1016/j.rse.2011.03.020, 2011.

Lefsky, M. A.: A global forest canopy height map from the Moderate Resolution Imaging Spectroradiometer and the Geoscience Laser Altimeter System, Geophys. Res. Lett., 37, L15401, doi:10.1029/2010GL043622, 2010.

Lloyd, A. H., Rupp, T. S., Fastie, C. L., and Starfield, A. M.: Patterns and dynamics of treeline advance on the Seward Peninsula, Alaska, J. Geophys. Res., 108, 8161, doi:10.1029/2001JD000852, 2002.

Lloyd, A. H., Yoshikawa, K., Fastie, C. L., Hinzman, L., and Fraver, M.: Effects of permafrost degradation on woody vegetation at arctic treeline on the Seward Peninsula, Alaska, Permafrost Periglac., 14, 93-101, doi:10.1002/ppp.446, 2003.

Loranty, M. M., Berner, L. T., Goetz, S. J., Jin, Y., and Randerson, J. T.: Vegetation controls on northern high latitude snowalbedo feedback: observations and CMIP5 model predictions, Glob. Change Biol., 20, 594-606, doi:10.1111/gcb.12391, 2013.

Malanson, G. P., Zeng, Y., and Walsh, S. J.: Complexity at advancing ecotones and frontiers, Environ. Plann. A, 38, 619-632, doi:10.1068/a37340, 2006.

Mathisen, I. E., Mikheeva, A., Tutubalina, O. V., Aune, S., and Hofgaard, A.: Fifty years of tree line change in the Khibiny Mountains, Russia: advantages of combined remote sensing and den- 
droecological approaches, edited by: Rocchini, D., Appl. Veg. Sci., 17, 6-16, doi:10.1111/avsc.12038, 2013.

Mette, T., Papathanassiou, K., and Hajnsek, I.: Biomass estimation from polarimetric SAR interferometry over heterogeneous forest terrain, Geoscience and Remote Sensing Symposium, 2004, IGARSS'04, Proceedings, 2004 IEEE International, 1, 511-514, 2004.

Montesano, P. M., Cook, B. D., Sun, G., Simard, M., Nelson, R. F., Ranson, K. J., Zhang, Z., and Luthcke, S.: Achieving accuracy requirements for forest biomass mapping: A spaceborne data fusion method for estimating forest biomass and LiDAR sampling error, Remote Sens. Environ., 130, 153-170, doi:10.1016/j.rse.2012.11.016, 2013.

Montesano, P. M., Nelson, R. F., Dubayah, R. O., Sun, G., Cook, B. D., Ranson, K., Næsset, E., and Kharuk, V.: The uncertainty of biomass estimates from LiDAR and SAR across a boreal forest structure gradient, Remote Sens. Environ., 154, 398-407, doi:10.1016/j.rse.2014.01.027, 2014a.

Montesano, P., Sun, G., Dubayah, R., and Ranson, K.: The Uncertainty of Plot-Scale Forest Height Estimates from Complementary Spaceborne Observations in the Taiga-Tundra Ecotone, Remote Sensing, 6, 10070-10088, doi:10.3390/rs61010070, 2014b.

Montesano, P. M., Rosette, J., Sun, G., North, P., Nelson, R. F., Dubayah, R. O., Ranson, K. J., and Kharuk, V.: The uncertainty of biomass estimates from modeled ICESat-2 returns across a boreal forest gradient, Remote Sens. Environ., 158, 95-109, doi:10.1016/j.rse.2014.10.029, 2015.

Moratto, Z. M., Broxton, M. J., Beyer, R. A., Lundy, M., and Husmann, K.: Ames Stereo Pipeline, NASA's open source automated stereogrammetry software, 41, 2364, 2010.

Naurzbaev, M. M. and Vaganov, E. A.: Variation of early summer and annual temperature in east Taymir and Putoran (Siberia) over the last two millennia inferred from tree rings, J. Geophys. Res.Atmos., 105, 7317-7326, 2000.

Naurzbaev, M. M., Hughes, M. K., and Vaganov, E. A.: Tree-ring growth curves as sources of climatic information, Quaternary Res., 62, 126-133, doi:10.1016/j.yqres.2004.06.005, 2004.

Neigh, C. S., Masek, J. G., and Nickeson, J. E.: High-Resolution Satellite Data Open for Government Research, Eos, Transactions American Geophysical Union, 94, 121-123, 2013.

Ni, W. and Woodcock, C. E.: Effect of canopy structure and the presence of snow on the albedo of boreal conifer forests, J. Geophys. Res.-Atmos., 105, 11879-11888, 2000.

Ni, W., Li, X., Woodcock, C. E., Roujean, J. L., and Davis, R. E.: Transmission of solar radiation in boreal conifer forests: Measurements and models, J. Geophys. Res.-Atmos., 102, 2955529566, 1997.

Ni-Meister, W. and Gao, H.: Assessing the impacts of vegetation heterogeneity on energy fluxes and snowmelt in boreal forests, $\mathrm{J}$. Plant Ecol.-UK, 4, 37-47, doi:10.1093/jpe/rtr004, 2011.

Osawa, A. and Kajimoto, T.: Development of Stand Structure in Larch Forests, in Ecological Studies, 209, 123-148, Ecological Studies, Dordrecht, 2009.

Payette, S., Fortin, M. J., and Gamache, I.: The subarctic foresttundra: the structure of a biome in a changing climate, Bioscience, 51, 709-718, 2001.
Ranson, K. J., Montesano, P. M., and Nelson, R.: Objectbased mapping of the circumpolar taiga-tundra ecotone with MODIS tree cover, Remote Sens. Environ., 115, 3670-3680, doi:10.1016/j.rse.2011.09.006, 2011.

Roy-Léveillée, P., Burn, C. R., and McDonald, I. D.: VegetationPermafrost Relations within the Forest-Tundra Ecotone near Old Crow, Northern Yukon, Canada, Permafrost Periglac. Process., 25, 127-135, 2014.

Shamsoddini, A. and Trinder, J. C.: Edge-detection-based filter for SAR speckle noise reduction, Int. J. Remote Sens., 33, 2296 2320, doi:10.1080/01431161.2011.614286, 2012.

Shimada, M., Itoh, T., Motooka, T., Watanabe, M., Shiraishi, T., Thapa, R. and Lucas, R.: New global forest/non-forest maps from ALOS PALSAR data (2007-2010), Remote Sens. Environ., 155, 13-31, doi:10.1016/j.rse.2014.04.014, 2014.

Simard, M., Pinto, N., and Fisher, J.: Mapping forest canopy height globally with spaceborne lidar, J. Geophys. Res., 116, G04021, doi:10.1029/2011JG001708, 2011.

Thompson, D. K., Simpson, B. N., and Beaudoin, A.: Forest Ecology and Management, Forest Ecol. Manag., 372, 19-27, doi:10.1016/j.foreco.2016.03.056, 2016.

van Aardt, J., Wynne, R., and Oderwald, R.: Forest volume and biomass estimation using small-footprint lidar-distributional parameters on a per-segment basis, Forest Sci., 52, 636-649, 2006.

Virtanen, R., Luoto, M., Rämä, T., Mikkola, K., Hjort, J., Grytnes, J.-A., and Birks, H. J. B.: Recent vegetation changes at the highlatitude tree line ecotone are controlled by geomorphological disturbance, productivity and diversity, Global Ecol. Biogeogr., 19, 810-821, doi:10.1111/j.1466-8238.2010.00570.x, 2010.

Wood, E. M., Pidgeon, A. M., Radeloff, V. C., and Keuler, N. S.: Image texture predicts avian density and species richness, PLoS ONE, 8, e63211, doi:10.1371/ journal.pone.0063211, 2013.

Wood, E. M., Pidgeon, A. M., Radeloff, V. C., and Keuler, N. S.: Remote Sensing of Environment, Remote Sens. Environ., 121, 516-526, doi:10.1016/j.rse.2012.01.003, 2012.

Wulder, M. A. and Seemann, D.: Forest inventory height update through the integration of lidar data with segmented Landsat imagery, Can. J. Remote Sens., 29, 536-543, 2003.

Wulder, M., Han, T., White, J., Sweda, T., and Tsuzuki, H.: Integrating profiling LIDAR with Landsat data for regional boreal forest canopy attribute estimation and change characterization, Remote Sens. Environ., 110, 123-137, 2007.

Xiaodong, Y. and Shugart, H. H.: FAREAST: a forest gap model to simulate dynamics and patterns of eastern Eurasian forests, J. Biogeogr., 32, 1641-1658, doi:10.1111/j.13652699.2005.01293.x, 2005.

Zhang, Y.: Sublimation from snow surface in southern mountain taiga of eastern Siberia, J. Geophys. Res., 109, D21103, doi:10.1029/2003JD003779, 2004.

Zwally, H. J., Schutz, R., Bentley, C., Bufton, J., Herring, T., Minster, J., Spinhirne, J., and Thomas, R.: GLAS/ICESat L2 Global Land Surface Altimetry Data, Version 34 [GLA14], Boulder, Colorado USA. NASA National Snow and Ice Data Center Distributed Active Archive Center, doi:10.5067/ICESAT/GLAS/DATA227, last access: 3 November 2014. 